\title{
Preteriception: memory as past-perception
}

\author{
István Aranyosi ${ }^{1}$ (1D
}

Received: 28 October 2019 / Accepted: 16 June 2020

(c) Springer Nature B.V. 2020

\begin{abstract}
The paper explicates and defends a direct realist view of episodic memory as pastperception, on the model of the more prominent direct realism about perception. First, a number of extant allegedly direct realist accounts are critically assessed, then the slogan that memory is past-perception is explained, defended against objections, and compared to extant rival views. Consequently, it is argued that direct realism about memory is a coherent and defensible view, and an attractive alternative to both the mainstream causal theories and the post-causal and constructivist views.
\end{abstract}

Keywords Memory $\cdot$ Episodic memory $\cdot$ Direct realism $\cdot$ Perception · Constructivism

\section{Introduction}

In this essay I am going to expound and defend a direct realist theory of episodic memory (which, henceforth, I will simply call "memory", except in cases when I need to distinguish it from other types of memory), that is, of memory of autobiographical events, objects, situations, places (Tulving 1972). There are several authors who have claimed to have subscribed to direct realism about memory, yet, it seems to me that their actual proposals are quite timid and not truly direct realist. ${ }^{1}$ I will discuss these views in due course, but for now, let me state the view in the shortest, simplest, and most memorable way: memory is past-perception, or, to introduce a neologism for it, preteriception..$^{2}$ Let me already pause here and explain

\footnotetext{
1 I will be using the expression "direct realism" throughout the essay, instead of "naïve realism", which has established itself in the perception literature, as this is the term theorists of realism (e.g. Bernecker 2008; Michaelian 2016) in the philosophy of memory seem to have adopted, and it is easier to keep things simple and not confuse the reader with different terms.

2 From the Latin "praeteritum", meaning "past events", and "perception".
}

István Aranyosi

aranyosi@bilkent.edu.tr; istvanaranyosi@gmail.com

http://istvanaranyosi.net/

1 Department of Philosophy, Bilkent University, 06800 Ankara, Turkey 
why I use the hyphenated "past-perception" rather than perception of the past. The view I will be explicating and defending is that memory is analogous to perception under a direct realist interpretation of the latter, not that it is perception per se, which happens to have past scenes rather than present ones as its object. If I offered the latter as a view, then I'd be forced to swallow the absurd consequence that when we look at a long-dead star in the sky we do not see it but remember it. This is why past-perception should be understood as sui generis; analogous to, but distinct from perception. So, the idea is that in some important respect memory is perceptual and its direct object is the past, on the model of direct realism about perception, where the objects of experience are constituents of it.

This is the thesis that I will explain and defend. First, I will tell a fictional story, which will be the main material for discussing the components of the theory; then, in Sect. 1, I will critically review five allegedly direct realist accounts of memory. This discussion will be followed by seven sections building up and defending my own direct realist view. Along this process, some of the currently influential views will be criticized and shown to fare less well than the view propounded here.

But first let me lay down the details of the main story we will be using in the paper to exemplify and discuss the components of the view.

Two nerdy CERN physicists, Nelu and Zoli, have been working on their secret side-project of building a time machine, and, finally, on a nice Sunday evening, they are ready to test it. They need to decide which time would be nice to visit. After a while, Nelu has the brilliant idea of traveling a week into the future to see the results of the great lottery draw worth a hundred million euros, then come back to the present and play the winning numbers. As it happens, the time machine can only fit one person. They flip a coin and it turns out that Nelu will travel to next Sunday to check the results of the lottery draw. Everything goes well. Nelu travels to next Sunday evening, watches the event on TV, records in with his smartphone, and travels back to this Sunday to tell Zoli what it was like to briefly visit the future.

Nelu makes it back safe and sound; however, he can't find the video recording of the winning numbers in his phone; the file got deleted somehow. Doing another test drive to the future is not feasible, because it requires months of preparation in the current stage of their project. So Zoli is pushing him to try to remember those numbers. Nelu can't remember them: 'I'm sorry I can't remember even one of them; I don't know why. I remember other details of the lottery draw broadcast on TV, but not the numbers. I remember the color and shape combination of the carpet in the studio (it was the same as the flag of Seychelles, which is interesting because it is a juxtaposition of two other flags - the Romanian and the Hungarian), but I simply can't remember the numbers!"

Nelu tries for days ... to no avail. They finally give up. Sunday arrives and they go for a beer at the local pub where they can watch the much-awaited lottery draw. After a few beers and when the draw is about to start, Zoli tells Nelu, half-jokingly: "what if you just remembered now the numbers ... I would kill you!". This prompts Nelu to automatically try to remember the numbers. He can't remember anything about the context of the lottery draw, about things like the carpet in the studio or the furniture; but, suddenly, he just remembers very clearly a woman drawing each of five winning numbers, one after another... He clearly remembers now the number 
drawn each time, except for the last number, when his mind gets blocked somehow. But then he suddenly remembers that he had a panic attack during the last number's draw from the urn, the kind of panic attack he has when he is confronted with the dreaded number 13-Nelu has been suffering from triskaidekaphobia, that is, extreme, pathological superstition and resulting fear of number 13. He draws the right conclusion, that the last number was 13, and imagines how the host draws the ball, opens it and shows " 13 " to the camera. Now he clearly remembers all the winning numbers ... He, of course, pretends it's not happening... Just to protect Zoli from a stroke...

\section{Extant, allegedly direct realist views}

I'm not the first one to (claim to) put forward a direct realist view of memory, or of remembering. However, to my knowledge, and if I am right in my characterization of the doctrine, this might be the first proposal of a philosophical theory of memory that is truly or genuinely direct realist, on the model of what direct realism in the literature on perception means.

After a brief review of the main tenets of direct or naïve realism about perception, I will consider a few recent proposals that are advertised under the heading "direct realism about memory", and point out how tame they are in comparison with how radical such a view should be, if we are to transfer it from the realm of perception to that of memory.

Direct or naïve realism about perception is a view about the perceptual relation, that is, about the relation between perceiver and perceived, or subject and object, or mind and world. It is a radical view, contrary to what the adjective "naïve" 3 might suggest. Its radicalness consists in taking perceived objects as literally constituents of the perceptual states (Martin 1997: p. 93). ${ }^{4}$ It is in this respect the perceptual analogue of the even more radical view that there can be singular thought, which is Russellian, that is, it has its object literally as a constituent. ${ }^{5}$

I'm aware that there is disagreement as to whether this idea of a perceived object being a constituent of one's experience of it is radical or rather commonsensical. Direct realists find it commonsensical and use this intuition as an argument for their view. On the other hand, those who are under the spell of the arguments from illusion and hallucination find this idea radical and hard to swallow. Anyhow, it is not important for our purposes to adjudicate this matter, but to simply point out that the idea of the object of a veridical experience being constitutive part of that experience is a core commitment of any view that deserves the name "direct realism".

\footnotetext{
3 Mike Martin's preferred way of referring to it, which has become standard by now, at least among the UK-based philosophers.

4 Tim Crane (2006) considers this, in effect, as making direct realism the only theory of perception in which there is a genuine perceptual relation. What Crane really means is that direct realism is the only philosophical theory of perception in which the perceptual relation is essential or fundamental to perception.

5 See McDowell (1982, 1984, 1986) and Evans (1982).
} 
Now let's move to the issue of memory. What would the analogue of direct realism about perception be in the case of memory or remembering? There are several proposals on the market that run under the heading "direct realism about memory". Let us briefly review them and see whether they qualify as true analogues of perceptual direct realism.

I will start with Mike Martin's own version of direct realism about memory (2001). I'm emphasizing “own”, because Martin is currently the most influential proponent of direct or naïve realism about perception. Though he doesn't call it as such, Martin defends a direct realist account of memory proposed in 1912 by Russell, which the latter would abandon by 1921. The core idea, at least in Martin's interpretation, was that memory is acquaintance with the past, which, in turn, is to be understood as preservation of a past episode of direct acquaintance with an event. Martin considers an apparent dilemma for this view but argues that it is based on a misconception of regarding the nature of imagination, episodic recall, and perception. More to the point, the dilemma is that either (1) a memory is more accurate the more it matches the original episode of perception, in which case it becomes phenomenologically very unlike a memory since it feels like present, not like past, or (2) it is or feels more about the past the least it matches the original episode of direct perceptual acquaintance, but then the idea of memory as retention of past acquaintance is not plausible anymore.

Martin offers a lengthy response to this dilemma in which the main point is that there is something like acquaintance with the past, which distinguishes memory from mere imagination, and it is phenomenologically present in the experience of episodic recall in guise of the particularity of the remembered object or event, in contrast to the lack of particularity of merely imagined episodes. How good this is as a response to the dilemma isn't my job to evaluate here. I only want to point out that the Russell-Martin thesis is a quite tame or timid version of a potential direct realism about memory.

Let me explain. The thesis is that episodic recall is direct in the sense that it inherits the directness from the original past event of perceptual apprehension. Thus Martin:

In perceptual experience, one is presented with its object as present to one, in relation to one's actual point of view. In episodic recall, although one is related to the same objects and qualities, one is not presented with them, rather one represents them, or rather recalls them as once presented to one's point of view. This phenomenological contrast, between objects as present in current sensory experience and as represented in recall, gives as a cognitive link to the past. In retaining the particularity of an earlier encounter, we retain a current cognitive link to a past encounter (...)

The distinctive phenomenology of our past experience is, then, the re-presentation of particular episodes in contrast, on the one hand, to the presentation of particular episodes in perception, and, on the other, to the nonparticular representation of experienced episodes in sensory imagination. (2001: pp. 278-9) 
This is a weak sense of directness, if at all. Since episodic recall is viewed as a representation, it follows that its analogue in the theories of perception should rather be a representational/intentional/content ${ }^{6}$ view. This is so even if, as Martin correctly points it out, it is a re-presentation, that is, a current conjuring of a once-presented scene (thus a scene that was a constituent of a perceptual state in the past). The fact that it originates in a presented rather than in a represented scene does not make episodic recall less representational and thus indirect on any standard account of mental representation. ${ }^{7}$

The next allegedly direct realist account of memory I want to consider is Sven Bernecker's (2008). Though he explicitly calls his view "direct realism", it is even more timid than Martin's approach. Besides, his view seems a bit confused when it comes to properly and correctly characterizing the source of the analogy, that is, the perception literature; this, obviously, results in a confused view about memory. Let me proceed to, first, pointing out these confusions about philosophical views of perception, and then expose the errors that result from them as far as memory is concerned.

In his discussion of perception (chapter 5), Bernecker contrasts direct realism with representative realism. He appears to (1) equate the latter with the sense datum theory, that is, with the view that there is a veil of perception, which stands between perceiver and the perceived object, consisting of mental particulars, and (2) equate sense datum theory with indirect realism (2008: pp. 62-63). ${ }^{8}$ There is a great deal of confusion going on here. Sense datum theories are not all realist views, not even indirect realist ones. Some (like Locke's) are, indeed, forms of indirect realism, but others, like the authors (viz. Howard Robinson) Bernecker lumps together under the heading "indirect realism" are antirealists; here is Bernecker (2008: p. 62):

While indirect realism was the standard view of early modern philosophers, nowadays direct realism is, once again, in fashion. Though there are still some indirect realists around (cf. Jackson 1977; Lowe 1992; O’Shaughnessy 1980; Robinson 1994) most contemporary theories of perception on the market see themselves as falling in the direct realism camp.

Jackson and Robinson, indeed, are rare exceptions in the literature in that they defend sense data, which are considered implausible oddities by most philosophers of perception today. Yet, it is not true that most philosophers of perception are direct

\footnotetext{
6 These are alternative names intentionalist philosophers of perception have used for their doctrine.

7 Crane (2006: p. 139) goes further (correctly, in my view) and claims that even object-dependent representations will not be good enough for a genuine direct realist to serve as the building blocks or foundation of the nature of veridical states; genuine perception must be completely non-representational. In psychology and in more empirically informed philosophy of mind we do have such examples of genuinely direct realist accounts of perception; for instance, James Gibson's ecological view of visual perception (1979), or Dan Hutto and Erik Myin's radical enactivism (2013).

8 To be fair, he does assert that "indirect realists" are not a monolithic block; however, the way they differ according to Bernecker is based on how much the posited sense data resemble the external objects. This indicates that he is equating indirect realism with views that are committed to sense data. This is not correct-see below.
} 
realists. On the contrary, I would say most of them are indirect realists, ${ }^{9}$ and one of the most popular forms of indirect realism is intentionalism, or the content view. This is the view that clearly rejects sense data, but it is not direct realist, because it does not consider external reality as literally being a constituent of perceptual states. ${ }^{10}$ Instead, it is a version of what McDowell (1982) dubbed a "highest common factor view" of perception. It is the denial of this thesis of a highest common factor in veridical perception and hallucination or illusion that would allegedly form the nature of perceptual states which makes a theory of perception direct realist. ${ }^{11}$ Why? Because it is this way that we can make sense of the radical idea that perceived objects are literally constituents of the perceiving mind; it is a form of externalism.

What, then, is Bernecker's view about memory, which he takes to be a form of direct realism? First, it is not about the nature of memory as such, but only about "the contents of memory". What he means by being a direct realist about the contents of memory is a very tame-I would say almost trivial—claim:

Direct realism maintains that the primary intentional objects of memory are past events rather than present internal representations (experiences) thereof. We have to internally represent a past event to remember it; but what we remember is the past event, not the internal representation. Memory is indirect in the sense that it involves internal representations; but memory is not indirect in the sense of involving a prior awareness of something other than the past event.

Memory is about past events, not about present representations of those events. This is an almost trivial thesis. I'm not aware of anyone defending the, admittedly odd, opposite view that memory is about the present representations. So, it is unclear to me why Bernecker even spends time discussing this under the heading "direct realism about memory contents" since it is an obvious and undisputed, intuitive, common-sense point about the intentionality involved in memory. Second, as it is apparent above, Bernecker's point is exclusively about intentional contents, which, as we have seen, would rather point to perceptual intentionalism (the content view of perception) as what Bernecker's model really is or should be. There is nothing direct about this doctrine regarding memory. Bernecker's view does not deserve the name "direct realism about memory".

\footnotetext{
${ }^{9}$ I should note that I am speaking from the point of view of a direct realist, unimpressed by the representationalists' own advertisement of their theory as being a form of direct perception. Aa an anonymous referee notes, representationalism is widely regarded as a reaction to sense-datum theories, which are often associated with indirect realism. I follow, however, direct realists (Snowdon 1992, and, more recently, Martin 2017 and Travis 2017) who are critical of this claim by representationalists.

${ }^{10}$ For an extensive criticism of the intentional theory, see Robinson (1994: ch 7).

11 This denial goes hand in hand with disjunctivism, that is, an analysis of appearance-talk as disjunctive, where the disjuncts are veridical perception and hallucination, and without there being anything reifiable or ontic in common between these disjuncts (the only thing they do have in common is epistemic, namely, phenomenal indistinguishability).
} 
A third account I want to consider was put forward by Wilcox and Katz (1981), the earliest to be explicitly called "direct realism about memory". While their view is, indeed, much closer to genuine direct realism than either Martin's or Bernecker's, it still suffers from not daring to go far enough on this path, if we are to focus on some subtleties involved in it.

The key issue according to Wilcox and Katz is time, or, more precisely, the way time and experience in time are assumed to work by the mainstream representational theory of memory, which is what the alternative direct realist theory is supposed to replace. The representational theory has it that experience happens always in the present and having as its object only presently existing items, hence, "experience of the past" can only mean experience of a present representation of past events. A novel, direct realist account of the experience of the past, on the other hand, would depict it as what Wilcox and Katz call the "apprehension of a sequential structure."12 Unlike simultaneous structure (which is not temporally constrained when it comes to the order of its apprehension-for example, seeing a multicoloured bird, where it does not matter in which order we experience its colours), sequential structure is temporally constrained, in that there is a specific order of apprehension which gives meaning to our experience; for example, a melody can be apprehended only by listening to the notes in a certain order, otherwise it is not that melody. Memory, then, is apprehension of a sequential order as the organism moves about in space and especially in time.

The way in which this is supposed to be an alternative to representationalism, according to Wilcox and Katz, is that there is no requirement of simultaneity between the process of remembering and its content, but rather the content stretches back in time. However, there is a subtlety here. What do they mean by "the content stretches back in time?". If what they mean is merely that the process or vehicle of remembering is temporally extended and follows a certain order given by the order of event sequences in the world, then the claim is not very exciting; no one would deny this, and, furthermore, it is compatible with mainstream representationalism. If, on the other hand, what they mean is that, literally, our mind stretches back in time when we remember, then it is a genuine direct realist view, but it should not have anything to do with whether we are dealing with an invariant sequential structure or not. Indeed, consider remembering my holiday in Tenerife last year; how my wallet got stolen in Los Abrigos while I was taking a photo of the beautiful view. There is nothing strict about the sequence of all the remembered events here. What matters is my memory of the one important event, namely, how I reach for my wallet in my shoulder bag and find the bag empty. So, the sequence is lacunary. Furthermore, I might also get the sequence "wrong", in the sense that it does not correspond to the actual sequence of events. All this does not change the fact that I do remember what happened.

Unfortunately, Wilcox and Katz do not offer something very illuminating when it comes to these questions:

$\overline{12}$ As per Gibson $(1966,1979)$ on perception of the world as apprehension of invariant structure. 
Broadly speaking, then, memory is not the resurrection of an SMR (stored mental representation $-n b$ ); it is rather the name we give to the apprehension of sequential structure. What exists is no longer confined to the present, but extends backward as part of a structure whose unique characteristic is that it is revealed in sequence. In essence, memory may be understood as the apprehension of an unfolding environment in which the past affects the present and the present affects the past.

Leaving aside the odd claim that "the present affects the past", there are two problematic issues in this quote. One is that it is not clear why unique sequentiality matters here at all. The second is their appeal to present effects of the past; there is a danger here, from the point of view of a would-be direct realist, of thinking of memory as access to the effects of the past rather than to the past itself. ${ }^{13}$ The problem is that thinking of memory as access to the effects of the past is no different from a causal theory, and the causal theory in the literature on perception is, or can be taken as, a rival of direct realism. ${ }^{14}$ No theory of memory deserves the name "direct realist" unless it adopts the idea that the relevant memory state is constituted by its object rather than caused by it. Child (1992: p. 304) eloquently explains the radical difference between causalism and disjunctivism, as first pointed out by Snowdon (1981):

(...) the disjunctive conception leaves no room for any causal element, since it provides nothing to be the effect in a case of vision. For there to be a causal relation there must be two separate states or events, one of which causes the other. But if the disjunctive conception is correct, the presence of an object and the experience $S$ has in seeing it are not two separate states of affairs; the experience is a case of $o$ 's looking $\mathrm{F}$ to $\mathrm{S}$; and that is a single state of the world, not a state of $S$ which might be produced in him by the action of $o$.

I conclude that Wilcox and Katz's proposal falls short of exemplifying a genuine direct realist view of memory.

A fourth view I want to discuss is the one put forward by Dorothea Debus (2008). Debus' view is, indeed, the closest to what I would consider genuine direct realism about memory (see the details below, in the next section), and I am discussing it not so much to criticize it per se, but rather to introduce my own direct realist view, which will involve elements that Debus does not cover in her analysis. Debus's

\footnotetext{
13 It is also interesting to note Wilcox and Katz, in their argument against representationalism about memory (pp. 236-237), adumbrate a version of Russell's time-lag argument, insinuating, therefore, that there is always delay and sequentiality, even in the case of perception, not only in that of memory. Bringing such an argument to its true consequences, would really mean that when looking at a long-extinguished star we do not see but remember. As mentioned in the introduction to this essay, I do not want to embrace such a view. I think we should follow common-sense and keep seeing and remembering as separate concepts, with distinct extensions.

14 There has been disagreement about whether direct realism, with its disjunctivie analysis of "looks" sentences, is compatible with the causal theory or not. I follow Snowdon (1981) in thinking that these two theories are rivals.
} 
direct realist view is, in my opinion, the best and most elaborate formulation currently in the literature, and is summarized by three claims, as follows:

(Relation Claim) When a subject R-remembers a past object (or event), the subject stands in an experiential relation - namely, a recollective relation - to the relevant past object (or event).

(Constitution Claim) An R-remembered object (or event) itself is a constitutive part of the relevant R-memory.

(Consciousness Claim) An R-remembered object (or event) is a constituent of the conscious recollective experience itself. This means that when a subject R-remembers a past object (or event), the past object (or event) is, for the R-remembering subject, immediately available in consciousness. (2008: p. 406)

R-remembering is Debus' term for episodic recall considered as involving a recollective relation to a past event or object-which is exactly what a direct realist about memory would say about remembering. The three claims express the commitments of genuine direct realism quite accurately, although the Consciousness Claim is not a component of my own view propounded here. ${ }^{15}$ My only problem is Debus' explication of the Relation Claim, where she thinks that there is a supervenience condition that R-remembering should satisfy. The issue is the conceptual connections between causation (or a causal connection requirement for remembering) and constitution. Whereas Debus thinks the R-remembering relation supervenes on the temporal, spatial, and causal relation that obtains between the remembered object or event and the currently remembering subject, I think the order of (metaphysical) explanation is the other way around: the temporal-spatial-causal relation that holds between a remembered object of the past and the currently remembering subject's mind is grounded in the subject's being in a direct remembering relation with that object, which relation, then, is fundamental, primitive, unanalyzable. ${ }^{16}$ I will say more about this below, but for now let's just point out that though Debus's theory is genuinely direct realist, it is, in my view, not the furthest one can go if one wants to be a direct realist about memory, the reason being that Debus does not recognize an important element of analogy that the theory of memory should borrow from direct realism about perception: the fundamentality of the experiential relation. Furthermore, it looks as though her view is close to being tributary to the causal theory, ultimately, given that it is the causal connection that seem to ground everything else about memory states.

\footnotetext{
15 I explain this below, in Sect. 4.

16 It was the first and most famous genuine direct realist about memory, Thomas Reid, who made this point about the fundamentality and unanalyzability of the remembering relation: "I think it appears, that memory is an original faculty, given us by the Author of our being, of which we can give no account, but that we are so made." (1983: 209). Debus takes this as a shortcoming on Reid's part, namely, as an instance of failing to give an account of memory. But this is not correct. What Reid says is that memory (episodic recall) is primitive and fundamental - just like perception is for us, direct realists.
} 
Finally, let me also consider a recent proposal by André Sant'Anna (2020), of what he calls a 'hybrid view of episodic memory', that is, one that is inspired by the perception literature and involves both a representationalist and (allegedly) a relationalist (direct realist) component. We don't need to delve into the details of the view to see that it is problematic; the main problem with Sant'Anna's proposal is that it is not genuinely direct realist. The reason for this verdict is the way he understands the idea of worldly events or facts constituting the memory states. Here are two relevant passages.

One clarification here refers to what I mean when I say that a memory is constituted by an event that took place in the past. I am using the term 'constitution' in a very general way, such that there are multiple ways in which a past event may constitute a present memory. One such way would be by means of a memory trace (Martin and Deutscher 1966; De Brigard 2014; Robins 2016). On this view, a past event is a constitutive part of a present memory because the latter preserves a causal connection to the former. The notion of constitution used in this case, however, is not that of material constitution. (2020: p. 6)

Regarding this quote, we should note that it is not at all customary in the literature on direct (naïve) realism about perception to stretch the concept of constitution and to water it down to such a degree that even a weak (modally speaking) relation like causation would satisfy it. On the contrary, the very idea of direct realism is to posit a strong relation of literal constitution (a part-whole relation).

Further, Sant'Anna argues for a notion of memory trace understood as a 'referential index', which is supposed to justify his point that events in the past can constitute the contents of memory. He explicates the notion of referential index as follows:

A referential index is a thing A that is responsible for pointing to the existence of another thing $\mathrm{B}$. A can point to the existence of B because A is existentially dependent on B, that is, A would not have been the case if B had not been the case. For example, smoke is a referential index for fire because it points to the existence of fire and smoke is existentially dependent on fire-i.e., assuming that there is smoke iff there is fire. What is important to note about referential indexes is that they can exist even in the absence of the things that they existentially depend on. That is, even in the absence of fire, smoke can still function as a referential index for fire, in the sense that it points to the existence of fire at a prior moment. (2020: p. 16)

This second passage is even more edifying about the fact that Sant'Anna's proposal fails to go far enough to qualify as direct realist. It is realist, for sure, but it looks, in effect, as nothing more than a standard representationalist theory. What he calls 'referential index' seems to be a representation understood as in an informational (Dretske 1981) and in an asymmetric dependence (Fodor 1987) theory of mental representation. Smoke indicates the existence of fire, thus carrying information about the latter. Similarly, Sant'Anna's existential dependence of the 
index on what it indicates is similar to Fodor's asymmetric dependence condition on representations (cf. that, e.g., the existence of the concept COW depends on the existence of cows, but the cows do not depend on the existence of the concept, even though the tokening of the concept can happen in the absence of cows).

Consequently, I am not convinced that Sant'Anna's proposal gets even close to the strictures of direct realism about memory. It does seem as merely a representationalist-causalist view.

Let us, then, proceed to explicating the direct realist view propounded herepreteriception. Our fictional story will mostly do for exemplifying the main components of the view.

\section{Personal time}

First, let us make clear that the term "past" in our slogan "memory is past-perception" should refer not to an objective past, but to the personal past. David Lewis (1976) made the distinction, in the context of a discussion of time travel, between external time and personal time. Roughly speaking, according to Lewis, when time travel happens, there is external time, which is the four-dimensional manifold of events which the unfolding Universe consitutes, and there is personal time, which is the time measured by the time traveller's wristwatch, and there is a discrepancy between these two times. In a typical sci-fi story of time travel, personal time is shorter than external time, so that, e.g., one travels in $2 \mathrm{~h}$ of personal time into the far past, which is, say, several years distance from the time of the traveller's departure.

The idea that memory is about personal time is well exemplified by our story. Nelu travels to next week's Sunday and back to the present. I did not specify how long it took for him, but it can be of any duration sufficiently shorter that the distance in external time between Nelu's present and next Sunday; for instance, we can posit that the whole trip to next week's Sunday and back took 5 min with Zoli and Nelu's time machine. What is important here is that when Nelu is back and Zoli asks the question "do you remember the numbers?", there is nothing unusual about the way the question is asked. More to the point, it does not matter that what Nelu was supposed to remember will occur in the future. It not only will occur but also occurred in the future. The future in external time is also past in Nelu's personal time.

This is important, because it is implicit or explicitly asserted in virtually all theories of remembering that memory is about personal time, though I haven't found an explicit argument for it. Your memories are not merely about events that happened, but about those that happened to you. What I am asserting here is not merely that it is wat happened to you in virtue of which your memories are yours - that seems trivial-but that what happened to you is what makes them memories simpliciter. The temporal dimension, then, falls nicely into place in this picture. The phenomenal pastness of remembering is pastness in personal time, not objective pastness. Of course, in normal circumstance, that is, in our existence, which does not involve time travel, these two pasts will coincide. But using the time travel example is a way to emphasize the personal character of memory. 
Now, this points to a notorious problem - that of the circularity that rears its (ugly?) head when one takes notions of memory and personal past together and tries to formulate an explanatory relation between the two. The problem is that "personal past" clearly involves the notion of a person, and, more disturbingly, that of a person persisting over time, which, in turn, involves the notion of being the same person as the one who experienced the relevant events in the past. If the account of the latter is "the person whose experience I remember", then we made it full circle, back to the notion of remembering. There are ways out of the circularity, ${ }^{17}$ but, more importantly, we could equally embrace it, and note that it is philosophically illuminating since it shows that the notions of memory, person, time and experience form a family of interconnected concepts, rather than each concept referring to a phenomenon that is contingently connected to the other phenomena picked out by the other concepts. This is better than some unexplained such connection between remembering and personal that we find in some of the extant views on memory. Michaelian (2016: p. 119), for instance, when explaining his simulationist theory of memory asserts that (a) experience is not necessary for remembering ${ }^{18}$ and, yet, that (b) "the simulation theory does not suggest that one can episodically remember events that do not belong to one' personal past" (emphasis in the original). This seems to me magical; how else than by reference to personal experiences are we to connect personal past and remembering? The issue is deeper than merely empirical - the question is: how are we to understand the notion of personal, once we assert that we can only remember the personal past, if not as what was once experienced by the same person as the one who remembers now?

\section{The metaphysic of temporal existence}

It shouldn't, though, be concluded that what I am propounding in guise of a direct realist view of memory is the idea that perceptual experience, which is to be understood the way direct realist does, is somehow fundamental and memory is derivative of it. This would be a misunderstanding. On the contrary, as already pointed out in my brief discussion of Debus' direct realist view, my view is that memory is direct, perceptual, and fundamental. The "perceptual" bit, in other words, is not to be understood as "derived from perception". Rather it should be understood as a sui generis form perception: past-perception, i.e. preteriception.

To say that this is fundamental is to say that it cannot be explained in terms of other phenomena, not even in terms of perception, even understood in the direct realist fashion. What is true about perceptual experience in connection with

\footnotetext{
17 See, e.g. Derek Parfit's (1984) theory of personal identity where this circularity of the Lockean memory criterion of personal identity over time is discussed and addressed by positing a neutral and impersonal notion of quasi-remembering, adopted from Sidney Shoemaker (1970).

18 I will come back to Michaelian's reasons for this and to his alleged counterexample to the thesis that past experience is necessary for remembering.
} 
preteriception is that it is a necessary condition for remembering, as I have pointed out in the previous section. But being a necessary condition is not the same as being definitional of or constitutive to remembering, let alone being the ground for it. ${ }^{19}$ The best thing we can do to understand preteriception, without wanting to and being able to explicate it via other phenomena, which then, are implicitly assumed to be more fundamental, is to get a grip on the analogy with perception. This, I trust, will be an illuminating discussion.

The core element of the analogy is this: while seeing, hearing, etc. is perceiving across space, memory understood as preteriception is perceiving across time. Perceiving an object across space involves the object directly, constitutively, as per direct realism about perception. Similarly, perceiving an object across time involves it constitutively. This already brings us to a standard objection to direct realism about memory, which Bernecker (2008: pp. 68-71) dubs "the co-temporality objection": how can an object of the past be constitutive part of a mental state that happens in the present? The objection is misguided. We can turn the tables on it by reverting to direct realism about perception and checking whether we could make sense of the objection-it is like asking: "how can the distant mountain that I am seeing now be a constitutive part of my visual state since it is at a distance from me?". If raising this question is not obviously meaningful, why would it be more meaningful in the case of preteriception, which is simply taken as a sui generis form of direct perception, except it holds across time rather than across space?

The objection, however, as Bernecker formulates it, involves the premise that objects of the past don't exist anymore, hence, they cannot be perceived now, in the present. Bernecker responds by denying presentism, that is, the view that only the present exists, and affirming eternalism, that is, the view according to which past, present, and future exist. If I was right in my criticism in Sect. 1 of Bernecker's way of understanding direct realism about memory, then he shouldn't have had to reply to the co-temporality objection at all since his view is not genuinely about the past being a constituent of present memory states, but merely about the past being an intentional object of these. ${ }^{20} \mathrm{Be}$ that as it may, I, on the other hand, do have to reply to this objection.

Prima facie, I would be tempted to say that even the presentist could be a direct realist about memory. Here is how it would go. Suppose you are a presentist. What you believe is that the past does not exist, not that it did not exist. All you need for preteriception is that the past existed, that is, that there be real events and objects in

\footnotetext{
${ }^{19}$ Cf. Kit Fine's (1994) example of Socrates's singleton and Socrates. Although this singleton necessarily contains Socrates, if he exists, it is, intuitively, not part of Socrates' essence, nor does it appear to be the ground for Socrates' existence.

${ }^{20}$ Intentional states are representational, and representations are precisely the kind of states that connect to the concrete world but also enjoy a certain kind of independence from it. Franz Brentano's notion of intentional inexistence is relevant here, which is the idea that the intentional object is contained within the intentional state without that meaning that it is (always) a thing in the extra-mental reality; it can sometimes be a non-existent item, like when one is thinking of the bogeyman. Similarly, when it comes to memory and its intentional objects, there is no question of anything like a co-temporality objection. Even if the past does not exist anymore, one can easily think about it, remember it etc. See Crane (1998) for a detailed discussion.
} 
the past, though they do not exist anymore. Preteriception is perception across time, not temporal teleportation; it is not some kind of magical time machine meant to teleport objects from the past into the present, but simply a perceptual relation whose relata are at different locations in time. Compare again with perception across space. Is there anything weird in saying that the mountain you see, which is located 20 miles away, is literally part of your visual state? If there is, it is not because of the 20 miles! If you have a hard time swallowing direct realism, then, of course, it appears weird to you to think of objects as literally parts of your visual states, regardless of how distant or otherwise these objects are. But, in any case, my point is that, on the assumption that you already are committed to direct realism about perception, you should have no problem in simply applying the recipe of a perceptual relation connecting relata at a distance in space to the case in which what separates these relata is not space but time.

However, once could insist that the co-temporality objection really works and that it forces one to adopt eternalism, the reason being that there simply cannot be a relation instantiated presently where one of its relata is not present; relations exist only if their relata exist. My reply is twofold. First, if presentism has the consequence that there is no relation one of whose relata is not present (indeed, there is a sizeable literature on this apparent and absurd implication of presentism, cf. Ingram and Tallant 2018) then presentism is worth discarding; it would have to deny, for instance, that there are any causal relations whatsoever since most present events are the effects of past events and causes of future events. In this case, then, there is nothing weird(er), pace e.g. Michaelian (2016: p. 63), about the alternative metaphysic of eternalism. Incidentally, then, the co-temporality problem is not specific to direct realists about memory; it will be a problem for the causal theory as well. Second, I do think that there is a distinction worth making, between a relation existing versus a relation holding, which is not made in the metaphysics literature (I introduce it in Aranyosi 2013: pp. 52-53, under the name "existing/standing" dichotomy for relations), but which in this case would be illuminating. We could say that a relation exists only if all its relata exist; but when a statement to the effect that some objects satisfy a certain relation is, intuitively, true or assertible regardless of the question its relata's existence, then we could say that that relation holds among those objects. A paradigmatic example of the former are spatial relations (e.g. "John lives $35 \mathrm{~km}$ away from Susan"), whereas examples of the latter include: "Sherlock Holmes is smarter than me", "Hulk is stronger than most of us", "God is more knowledgeable than any of us".

I conclude that the co-temporality objection is, at best, question-begging (it says, roughly, that direct realism about memory is false). 


\section{Phenomenology of remembering}

The main argument for naïve realism about perception -which one then wonders if it transfers to direct realism about memory-is based on phenomenology (Genone 2016). ${ }^{21}$ More precisely, the claim is that our phenomenology of perceiving objects in the environment presents, rather than represents, reality. We have a naïve realist attitude towards what we perceive, and nowhere in our everyday engaging with reality does anything like a sophisticated veil of perception makes its way. Does this argument transfer to the case of memory? Debus (2008) seems to think so, given the above-mentioned Consciousness Claim of hers, according to which not only is the object of remembering a constituent part of the state of remembering, but it also is a constituent part of the conscious experience of remembering that object, thus determining its character.

Now, if I earlier said that Debus view is not radical enough (because it is basically a version of causalism), now I have to say that in respect of the issue of phenomenology, it is more radical than what I am ready to accept. The Consciousness Claim has the consequence-accepted and defended by Debus (2008: pp. 421-9) - that the numerical distinctness of two objects that are the cause of the two conscious experiences of remembering them, indiscriminable by the subject, entails the phenomenological difference (i.e. a difference in what it is like to remember each) between these two experiences of remembering. I am aware that this is supposed to emulate the counterpart thesis in the philosophy of perception, to the effect that phenomenology is also constituted, and thus determined (not merely caused), by the object of perception, but it is this aspect of the original direct realist thesis in perception that some theorists are not ready to accept and argue that direct realists should not insist on holding it (e.g. French 2018).

Next, I want to consider an objection, which I will call "the phenomenological objection". What it says is that the phenomenology of remembering is not that of perceiving; perception's phenomenology is synonymous with the feeling of presence and clarity, whereas the pastness, blurriness, and faintness of the remembered event or scene is exactly the opposite. So, remembering can in no way be some kind of perception.

There are two things to say in response. One focuses on common-sense facts about perception, the other on such facts about memory.

First, perception. It is true that, say, visually perceiving a middle-sized dry object in close enough proximity, in normal conditions of illumination, by a normal, healthy, undistracted human subject, goes hand in hand with the above-mentioned phenomenology of presence and clarity of the perceived object. But this, of course, doesn't mean that this phenomenology is essential or even typical to perception. Most people, most of the time, see plenty of objects in abnormal conditions of illumination (e.g. darkness, fog). They also see very large and distant objects (e.g. mountains, skyscrapers, the Moon). Many people are also myopic. And some people

\footnotetext{
21 Thanks to an anonymous referee for asking me to say more about the potential phenomenology-based argument for direct realis about memory.
} 
suffer from derealization disorder. Yet, they see. There is no question about this. How all these people see is another matter; their visual field is imprecise, blurry, and the objects sometimes appear as unreal (the core symptom in derealization disorder). Nothing like the clarity, precision and presence the objector supposes to be the core phenomenology of perception. Now, of course, there is a sense of presence to the perceptual object; a pretty trivial one, that when we perceive, we are aware that an object is present rather than absent (like in imagination) or past (like in memory).

Second, memory. In many ways, memory resembles perception when it comes to the "how" rather than the "what" of its functioning. As mentioned before, the core analogy between perception and memory is based in the analogy between space and time. Hence, just as the way we perceive an object varies the farther away the object is in space, so too in memory of it, temporal distance (among other variables) will play a role in how we remember it. Mutatis mutandis for other phenomena that constitute the "how" of perception and of memory. The essential way in which they differ, of course, is in the "what"-perception is of things present, preteriception is of things past. This difference in the temporal location of their respective objects is what accounts for preteriception not being merely a derivative phenomenon, an offshoot of perception, but a distinct faculty in its own right, as Reid insisted more than two hundred years ago.

Finally, to put further phenomenological worries to rest, it is unclear why and how this type of objection is really directed at realism. It would more properly be directed at antirealist theories, that is, theories that put forward a reduction of memory to mind-dependent processes or states. For instance, walking in Hume's footsteps, various constructivisms about memory try to reduce it to person-level, psychological phenomena, like "episodic imagination" (Michaelian 2016), or to neural phenomena, such as certain activation patterns in the default mode network (Schacter and Addis 2007). While for these accounts it is imagination that looks like a good candidate for memory to be reduced to, for our objector it is perceptual phenomenology. Anyhow, among all theories, it is precisely direct realism that is most opposed to the idea of reducing memory to anything else, be it phenomenological, psychological, or neurological. Consequently, it is only to be expected for preteriception to differ in some ways from perception phenomenologically.

\section{Causal versus constitutive views}

Let's move now to the issue of causation and the causal theory of remembering, in contrast with the view proposed here. As highlighted in Sect. 1, Debus's view is, indeed, the best account to date of what genuine direct realism about memory should look like. Yet, unfortunately, she ultimately caves into the causal theory in that she seems to think that the causal link between the object of memory and the present act of remembering is essential to successful remembering. In other words, what appears to make a successful act of remembering be about a particular object (or event, or scene) is the existence of a causal chain from the past into the present occurrent mental state, not the existence of the object itself. The fact that we many times make an effort to remember an object, an event, a scene, or aspects of a scene, 
etc., indicates that we are implicitly searching for some causal anchors, that is, what psychologists and philosophers of memory have been calling "memory traces". ${ }^{22}$ Memory traces play an essential role in the influential causal theory of remembering elaborated by Martin and Deutscher (1966).

Though such a causal link is, arguably, indeed present in most of our successful acts of remembering, I do not think it is essential or constitutive of them. But even if I am wrong about this, it is still more correct to say that direct realism and the causal theory are distinct views, and that if one is a genuine direct realist, then one is committed to a stronger relation than causation as the basis or ground for successful remembering; that relation is one of being a proper part of, rather than merely being a cause of. ${ }^{23}$ The causal relation is typically considered contingent and hence not able to confer identity and individuation to its relate; on the other hand, constitution, proper parthood, composition, are stronger relations in that their holding confers such identity and individuation conditions.

But, as it happens, I don't think I'm wrong about this; that is, about the causal link not being a ground for remembering. In our story, Nelu first remembers the colors and pattern of the carpet in the studio but not the numbers. Later, when watching the lottery draw on TV, he suddenly remembers the numbers but does not remember anything else about the studio. It is an ordinary and frequent phenomenon for us not only to remember something, but to remember it again, later-to re-remember it. How to individuate memories that are re-remembered? What makes it the case that it is the same thing that we remember when we re-remember something, although the act itself of remembering is a new and distinct one? I call this "the diachronic identity problem", and I think any theory of memory should be able to offer a decent account of it. ${ }^{24}$ I will come back to the issue of whether any theory except the one I am defending here is able to do this, but, for now, let us just focus on this bit of the story and its implications regarding the causal theory.

There is a widely shared view in the literature on the metaphysics of causation to the effect that events are causally efficacious in virtue of their properties (Kim 1973). An event doesn't just cause another simpliciter, but it is some property of the former that is relevant in bringing about the instantiation of a property of the latter. The way I set the story up is such that there is no property overlap-of the causally relevant kind for either perception of preteriception-between Nelu's two episodes of remembering. Yet, by postulation, he is remembering the same event, namely, the lottery draw that will take place next Sunday. First, he remembers some aspects of this event (the carpet in the studio), then later he remembers some other aspects (the numbers). There is no overlap of properties except for ones that are not relevant for the episodicity of the act of remembering (like, e.g. that there was a studio, that

\footnotetext{
22 For a review of the literature on memory traces, see De Brigard (2014).

23 Things get even clearer if we go back to rival theories of perception. In that literature, the causal theory is sometimes considered a rival of direct realism. See Child's (1992) comparative analysis of naïve realism (in guise of disjunctivism) and the causal theory of perception.

24 There is no counterpart of this problem in perception, in my opinion, where perceiving an object from a different place or at a different time counts as a distinct experience from the original. In this respect perception and memory are disanalogous. See Sect. 8 for more on this issue.
} 
there were people in the studio, that the lottery draw happened in Bern, and so on). What, then, explains the fact that Nelu is re-remembering the lottery draw? It can't be a causal chain that connects both of his acts of remembering and the lottery draw since, by design, such a chain does not exist. ${ }^{25}$ It must be the event itself, the lottery draw per se. Nelu pretericeives the lottery draw twice. ${ }^{26}$ In typical cases this also involves a causal chain to the pretericeived event, but it is not necessary. We pretericeive in virtue of the mere existence of the past event, which is literally a constituent of our pretericeptive mental state.

Now, even if one were to accept the above verdict and the distinction between causal and constitutive views about remembering, all the non-direct realist views seem to, arguably, fare better than the direct realist one when it comes to false memories. The causal view will posit representations as the relevant unit of analysis, and standard representations like the ones assumed in classical cognitive science ${ }^{27}$ are best suited to deal with the problem of false memories, just like they are supposed to deal with false perceptions (illusions and hallucinations) in the case of perceptual states. Similarly, constructivist views, like simulationism, will be a fortiori better equipped to deal with such cases of misrepresentation, as they don't even require a minimal element of realism in guise of a causal chain to a concrete event [e.g. what Michaelian (2016: chs 5 and 6) calls "radical generationism"].

Direct realism about memory is going to deal with this problem just like it does with the analogous problems in perception, by postulating disjunctivism, Disjunctivism states that there is no common factor to veridical and non-veridical perception/ remembering, hence these two types of states are radically different in nature. The problem is that this seems to go against both naturalism and common sense. I dedicate an entire paper to defending disjunctivism (Aranyosi 2020), so here I will just mention the following. When it comes to common sense, it is not obvious that ordinary people would classify false and veridical memories as having the same nature; we need well designed empirical studies to support such a claim. ${ }^{28}$ Secondly, the issue of a conflict with science does not really arise, in my opinion. Direct/naïve

\footnotetext{
25 To clarify: the reason there is no such single causal chain connecting the two episodes of remembering is simply that there is no common causally relevant property between the two episodes; it has nothing to so, in other words, with issues related to the temporal order (future-to-past) in objective time of cause and effect.

${ }^{26}$ One could, of course, deny that the two acts are one memory, based on a more precise typing of events, according to which the "carpet color" aspect and the winning numbers" aspect are distinct events in their own right. The idea is, then, that whether there is one event or more depends on how precisely events are typed (i.e. whether they fall under a single or under multiple types, or how fine-grained a conception of events we adopt). I do not deny the coherence of this. But all I need for my argument is that it makes sense to talk about a single event "the lottery draw", as well as it might also make sense to decompose it into multiple events, and we need to circumscribe and individuate the reoccurrence of the memory of this single event.

27 Nonstandard representations are de re, that is, object-dependent for their existence. See, for instance, McDowell (1984, 1986).

28 Vilius Dranseika's (2020) study is a start. Dranseika's results contradict some my claims in this paper regarding "common sense", but the issue ultimately will depend on how robust the findings are when tested in the future in various cultural contexts and with various question sets that subjects are required to answer.
} 
realism, disjunctivism, and similar views are highly abstract metaphysical ones that do not really engage with science at all. However, if forced to answer the question "is disjunctivism compatible with the cognitive neuroscience of memory?", I would say "yes". The reason is that direct realists can unproblematically accept that there is a common cognitive and neural mechanism to false and veridical remembering (see the next section), but that aspect of remembering does not exhaust the concept of remembering. The extra element is metaphysical and is not supposed to engage with science at all; it is needed for a what accounts for a philosophically correct theory.

\section{Meminization}

Let me introduce another neologism-meminization. ${ }^{29}$ It refers to whatever is going on phenomenologically, psychologically, and neurologically in the process of successful or unsuccessful remembering, in remembering and in misremembering. Some examples of what is going on in this complex process of meminization are:

Phenomenologically: images, sounds, smells, the feeling of familiarity, the feeling of pastness, the feeling of deja-vu

Psychologically: the belief that these events happened to me, the disposition to assert that these events happened to me

Neurologically: activity in the default mode network, activity in the hippocampus

Let us call a meminization which is an instance of successful remembering "a veridical meminization", and one which isn't "a non-veridical meminization", which can further be divided into illusory meminization (a.k.a. misremembering) and hallucinatory meminization (a.k.a. confabulation). ${ }^{30}$

What I said in the previous section about what a direct realist would put forward as a solution to the problem of diachronic identity of memories can then be formulated as:

A token meminization $m_{1}$ is the same memory as a token meminization $m_{2}$ iff the object that partly constitutes $m_{1}=$ the object that partly constitutes $m_{2}$.

\footnotetext{
${ }^{29}$ From the Latin "memini", meaning "I remember", "I am mindful of".

30 A referee asks whether this is not tantamount to asserting that there is a common factor to all these states (viz. mminization), which is contrary to the very idea o direct realism. No. The claim I am making in this paper is and in this section on meminization is that whatever is a common factor to, say memory and confabulation, it is not part of the nature of memory, not what makes a memory a memory. Is this claim supported by common sense? Dranseika's study, mentioned in a previous footnote, seems to indicate a negative answer to this question. Is it supported by memory science? No, because memory science does not have conceptual analysis as its topic; its topic is meminization, not whether meminization is the same concept as remembering (science assumes they are the same, but science is not the same endeavour s philosophy, though they overlap).
} 
Now, there is a group of theories of episodic memory, which I would call "naturalistic-constructivist", which run under the name "simulation theory" or "simulationism", and whose core idea is to simply identify remembering with meminization, where, of course, the character of meminization is accounted for in various ways by different theories. These are theories that, in my view, commit a naturalistic fallacy. What is common to them is the move from "there are some empirically identified neural phenomena related to how people's memory works" to "therefore, whatever analysis of what memory is we come up with should be a slave to these empirical facts-these facts are sacred, and if they imply some crazy and counterintuitive revision of our concept of memory, then so be it, we should adopt a revisionary view of memory".

The specific piece of empirical finding that simulationists got so impressed by is that at the neural level the mechanisms that realize what is going on during meminization are the same as those that realize imagination. Simulationists pay tribute to psychologist Endel Tulving's latest definition of memory as "mental time travel" (Tulving 2011; Michaelian 2016). Mental time travel is these theorists' version of what I have called "meminization", and it is, according to them, the capacity to imagine both the past and the future. The basic motivation behind identifying memory with mental time travel is the growing empirical evidence of a common neural-level system responsible for both meminization and imagination. From the existence of this common system the simulationist infers that memory is a kind of imagination. This seems to run against common-sense since memory and imagination are, prima facie, distinct faculties. ${ }^{31}$ Reid, for instance, thought this is as clear as that colours are distinct from sounds and flavours. In his fierce criticism of Hume's constructivism about memory he writes:

Everyone knows perfectly what it is to see an object with his eyes, what it is to remember a past event, and what it is to conceive something that doesn't exist. These three are quite different operations of the mind, and everyone is as certain of this as he is that sound differs from colour and both differ from taste. (Bennett 2017: p. 158)

I do not expect constructivists to be impressed by this argument from common-sense since they've already explicitly given up on common-sense in the name of "naturalism". Yet, I want to point out the more abstract, theoretical, and general point that it is hard to see why some contingent empirical facts about human meminization

\footnotetext{
31 I am aware that there is an emerging critical literature on what armchair philosophers have long assumed to be the case when it comes to various aspects of episodic memory; assumptions include: that memory is factive, that a necessary condition of memory is experience, and that memory is a different faculty and a distinct concept from that of imagination. Filipe De Brigard (2014) has a rich and illuminating critical discussion of the last one, arguing, among other things, that while the thesis that imagination and memory are distinct faculties was assumed as obvious by some philosophers, there were others, like Hobbes and Hume, who thought and argued for exactly the opposite. This paper is not the place to adjudicate the many arguments pro and contra the thesis. I myself intuit that even the fact that we have different names for them shows that imagination and memory are distinct both as psychological faculties and as concepts.
} 
should be considered so important as to be taken to form the core rather than the periphery of the concept of memory, so that the belief that they are part of the concept would be less revisable than the ordinary, common-sense concept itself. What if some intelligent and communicative alien life forms showed up, and they did not exhibit similar neural-level meminization mechanisms when telling us how trees and rivers look like on their planet? Let's say they completely lacked the brain structures that in us realize episodic imagination of things that do not exist. Furthermore, let's suppose that even at cognitive level they differed from us very much; for example, their minds could not generate content (imagine, simulate), so generativity was simply missing from their potential memory system. Would we say they are not really remembering how trees and rivers look like on the planet they came from? That is what the naturalistic constructivists would have us assert, which is absurd.

Next let us consider the simulationists insistence that there is no asymmetry between past and future "mental time travel", and that, consequently, past-directed and future-directed imagination should be considered two sides of the same coin of meminization, hence, of memory. Simulationists seem to have a hard time with their balancing act of staying away from asserting that future oriented imagination is literally about a concrete, existing future while insisting that, ultimately, memory is nothing else but these acts of meminization (plus a condition of approximate match between the content of meminization and the concrete past-more on this below). Here is a revelatory quote from Michaelian:

(...) the point to note is simply that episodic memory is currently viewed, by most psychologists working the area, as one instance of a more general capacity allowing the agent both to re-experience past episodes and to "pre-experience" possible future episodes. (2016: p. 98)

It is not a coincidence that Michaelian uses quotation marks when referring to "preexperiencing" the future. He is speaking metaphorically. But, then, I say: he should speak metaphorically all the way through, including when talking about memory as "mental time travel"! Let me explain.

I can't make sense of the expression "future-oriented imagination" unless I'm talking metaphorically about the future. The future does not yet exist, so, strictly speaking, I can't have attitudes towards the future, only towards an imaginary future. If simulationism were right, and there were no asymmetry between "futureoriented" imagination and past-oriented meminization, then I should say the same thing about the past, viz. that when I say "past-oriented meminization", I must be speaking metaphorically. But I'm not. The reason is that unlike the future, the past exists or existed-it happened. Direct realism in guise of preteriception can account for this asymmetry very smoothly and elegantly. Simulationism must deny the asymmetry, which goes against basic metaphysical truths, such as that the past is closed whereas the future is open. Conversely, if simulationism were right about the symmetry between past- and future-oriented attitudes, then, given that simulationists also assert that a mere matching of content between meminization and the personal past is sufficient for the meminization to count as remembering (more on 
this below), we should find ourselves possessing magical powers of foreknowledge, of having access to the future, whenever such content-matching with the personal future occurred. ${ }^{32}$ This is obvious since foreknowledge is simply a mirror image of remembering, if simulationism is right. This does not square well with either common-sense or with science. ${ }^{33},{ }^{34}$

\section{Magical connections}

Simulationism's formula for remembering seems to be this:<meminization $>+<$ content of meminization matching episode in personal past $>=$ memory. As I pointed out in Sect. 2, when I first mentioned Michaelian's (2016) simulationist view, the connection is magical. We are not told why a mere matching of content with an event in the personal past would be sufficient for memory; it is not only counterintuitive, but also, more importantly, unexplained. Similar perplexities emerge from Michaelian's alleged counterexample to the very intuitive idea that experience is what makes a past personal. He puts forward the following story:

Consider the sort of procedure used by eyewitness memory researchers to implant false memories of whole episodes, such as being lost in a shopping mall as a small child (Loftus 1993). According to the simulation theory, what goes on in such cases is not that the subject fails to remember. But simply that he misremembers (...) Suppose, now, that a subject on whom the procedure is used actually was lost in a mall as a small child, too young to count as having experienced the episode, strictly speaking. The simulation theory implies that in such a case, the subject does not even misremember - he simply remembers the episode. The he did not actually experience it makes no difference.

The background to the point about the child having been too young to be able to experience things, strictly speaking, is that Michaelian earlier distinguishes a strict and a loose sense of experience, so that, for instance, small children do not count, in the strict sense, as having experiences at all. The idea is that you might experience

\footnotetext{
${ }^{32}$ To be more precise or more pedantic: the faculty we would possess would not be very useful since whenever we "meminized" about the future, we would not know whether the content of our meminization matches anything in the future or not. But, in hindsight, when it does, we should say that, indeed, at some point in the past we knew what events some future point in time would contain. Such consequences just further indicate how inadequate simulationism is.

${ }^{33}$ If we did have such foreknowledge, then, yes, memory would be something else than it actually is. Reid makes this point when he says: "We are so constituted as to have an intuitive knowledge of many past things, but we have no intuitive knowledge of the future. Perhaps we could have been so constituted that we had intuitive knowledge of the future but not of the past; and that constitution wouldn't have been any harder to explain than our actual one is, though it might be much more inconvenient! If that had been how we were built, we would have found no difficulty in accepting that God can know all future things, but much difficulty in accepting his knowledge of things that are past." (Bennett 2017: p. 136).

${ }^{34}$ For an overview of the debate between those who think there must be an asymmetry between pastand future-oriented mental states in the context menta time travel theory, see Perrin and Michaelian (2017). For my own arguments for the reasonableness of accepting such an asymmetry, see my 2020.
} 
something that is $F$, but not qua $F$ at the time when you do not yet possess the concept associated with $F$, while, later, you are asked whether you can remember the $F$, at a time when you do possess the concept associated with $F$, thus be able to remember the $F$ qua $F$.

Though I do find Michaelian's understanding of misremembering problematic, I won't attack it. Rather, I just want to point out that if he is right about the interpretation of this story, then some other prima facie odd consequences follow. The verdict resulting from the simulationist view regarding the part of my story where Nelu remembers his triskaidekaphobia and his panic attack caused by it during the lottery draw (and as a result infers that the last number of the draw, which he couldn't remember, must have been 13) is that Nelu genuinely episodically remembers the number. This is so because the two conditions for remembering which the simulationist puts forward are satisfied: the draw of number 13 happened (and it happened "to Nelu", as it were, i.e. it is an event in his personal past) and what Nelu is doing now is meminizing number 13 , that is, conjuring up an image of " 13 " in his imagination. Our verdict, on the other hand, is that he remembers the number at most semantically (by deployment of memory of facts, plus, of course, basic inferential knowledge) but not episodically. Our view is that Nelu forgot what the last number of the draw was, and still can't episodically remember it, that is, he can't pretericeive it; yet, he can semantically remember it via an intricate path of inferential steps connecting his known triskaidekaphobia to what number must have been drawn.

Our story is theoretically coherent and credible. Nelu's knowledge of his own triskaidekaphobia and the inductive and deductive consequences that flow from it do not constitute the right ground for Nelu's remembering number 13 to count as preteriception, i.e. episodic memory. This is why Nelu counts as having forgotten and still not remembering in the episodic sense; he did experience the number at the time of the draw but forgot it, as he can't pretericeive it.

\section{Factivity and re-remembering}

Let us return, in this last section of my essay, to the problem of re-remembering, which we touched upon in Sect. 5. I said there that I would come back to this problem and argue that direct realism tackles it better than other theories. It is easy to see why. Let us consider three rival views to direct realism: the causal theory, the simulation theory, and the generative-causal hybrid theory. The idea is that whenever these theories are able to account for re-remembering, that is, for diachronic identity of memories, they do so in virtue of a component of theirs which is the core or defining element of direct realism: factivity. Before I explain this, let me pause a bit and make it clearer what re-remembering is supposed to mean in my view.

According to the view propounded here, remembering is past-perception, which means experiencing an event from a certain distance in time, the remembered event having occurred before that mnemonic experience or meminization. Perceiving an event means experiencing it while it occurs, that is quasi-simultaneously with its occurrence. Pretericeiving an event means experiencing it later, that is, from a later point of view. The same event can be remembered differently at different times by 
the same person, as well as differently by different people. The former, however, is special. Although we ordinarily say that we share some memories with someone else, it is not strictly speaking one memory that we somehow tap into. We are not the same mind. Conversely, if we -you and me-doubted that we are distinct minds, then when we shared a memory of an event that we experienced together, we would consider it one memory. Things are different with the same person having the memory of a certain event at different times. Here we have one mind persisting over time, whose temporal parts share a memory, numerically the same one, I claim, even when its conscious content (the "how" of remembering) changes radically over time. Thus, consider a unique and vivid event, such as the 9/11 terrorist attack on the WTC towers, as experienced by an eyewitness in New York City, which is then remembered and re-remembered at various points in time. Even if this person reremembers the event radically differently, I would say that it is the same memory that he has at those times. If this is agreed, then the question is what could the basis of this sameness be? I argue below that it is not something that has to do with meminization (which constructivists are exclusively focusing on when analyzing the concept of memory), but an extraneous condition (that is, external to the meminization itself), namely, the event itself.

This brings us back to factivity. Factivity is a property of certain mental acts that wear their success sense $\mathrm{e}^{35}$ on their sleeve. Seeing is such a mental act. To see is to succeed in seeing. You can't be caught seeing something. It is not a process. It is like winning. You can't be in the process of winning; you won. Arguably, to remember is also such a verb of success. You are not in the process of remembering. You simply remember. Or not. If this is the case, or if we assume this is the nature of the concept whose explication we are attempting here, then it is in virtue of what makes remembering a success that we can individuate memories. And this is simply factivity, that is, the dependence of the state's instantiation on facts, on truths.

If we consider now each of the three rival theories, it is apparent that they succeed in diachronic identity of memories precisely because, or to the extent that, they include factivity as a condition on remembering. Take the causal theory of Martin and Deutscher (1966). As we have seen in Sect. 5, when I discussed Nelu's case of first remembering and then forgetting the color pattern of the carpet, individuation does not require a causal chain that runs through all the episodes of re-remembering the same thing. Now, typically, of course, there will be such a causal chain. But if I am right, two temporally distinct meminizations will count as the same memory not in virtue of this causal chain but in virtue of the mere origin of that chain, that is, the object or scene itself which is remembered. Now take the simulation theory (Szpunar 2010; Michaelian 2016). What makes, or would make, this theory bold and interesting is the radical and revisionary idea that memory is, basically, meminization. However, simulationists will soften this stance in difficult cases, like the question of diachronic identity. They will insert as a condition on remembering the match between the facts of the past and the current meminization. This is nothing else but factivity as a condition on remembering. Finally, take a hybrid view, like

$\overline{35}$ Cf. Gilbert Ryle (1954) on the distinction between verbs of success and "try" verbs. 
the generative-causal theory (Michaelian 2016: ch. 5.8). It is similar to the causal view in that it posits memory traces as necessary for remembering, but it also adds the idea that memory is generative rather than preservative, which is what empirical studies have consistently proven. Anyhow, if this type of view has anything to say in response to the problem of re-remembering, it will coincide with what the causal theory says, and it will state that it is the common origin of the memory traces that can account for sameness of memory over time.

That it is the origin of the memory traces or the past facts which current meminizations match that are responsible for the identity and individuation conditions of memories might seem trivial. But it is only trivial under the rival theories. Under direct realism, understood here as memory in guise of preteriception, it is not trivial, but constitutive of the view itself.

Let me end with a problem for preteriception. It is a problem that we inherit from direct realism about perception. It is unavoidable by any externalist view of the mind. At the same time, it is a cost that, as I will now argue, is easier to bear in the case of memory than in the case of perception, which makes direct realism an even more appropriate theory for memory than for perception. The problem is that if one adopts direct realism about perception, then one should be prepared to acknowledge that introspection of one's experiences says close to nothing about the nature of sensory states (cf. Martin 2004). The reason is that (a) the direct realist's response to the argument from hallucination is disjunctivism, which implies that there is no common nature to hallucinations and veridical experiences, and (b) the direct realist claims that phenomenal properties (e.g. what it is like to see red, or to smell a rose etc.) are properties of the objects that are constituents of the experiences. Since, by assumption, there is no way for the subject to distinguish a veridical experience from a matching hallucination, the subject lacks knowledge, if he relies merely on introspection, of the nature of phenomenal properties, which constitute sensory experience; hence, the subject lacks knowledge of the nature of sensory states. This is a problem for direct realism and a cost it must pay, compared to common factor views, which imply that the nature of sensory experience is exhausted by the introspectable phenomenal properties of experience (hence veridical and hallucinatory experiences do not differ in nature). ${ }^{36}$

Translated into the context of memory, the problem seems to be this: whereas, say, if constructivist views are right, the nature of memory is the same as the nature of meminization, which, in turn, is knowable by introspection, were one to adopt the preteriception view, the remembering subject would lack knowledge of the nature of meminization, if his methods of inquiry were restricted to introspection; since meminization means, among other things, conjuring up sensory qualities, we end up with a remembering subject who does not know the nature of sensory qualities instantiated in the past.

\footnotetext{
${ }^{36}$ Martin thinks that this lack of knowledge of the nature of sensory states is a problem for all theories, or at least that "all views must concede that some sensory appearances seem other than they are (...)" (2004: p. 85).
} 
This is less of a problem, I want to argue, than it was in the case of perception, for two reasons. One is that since preteriception is so different from and less vivid than perception (cf. our Sect. 4), there is no temptation and no reason, unlike in perception, to give an account of the phenomenal properties of preteriception in terms of the instantiated properties of pretericeived objects. Even in perception, we, as direct realists, have a reason to explain phenomenal properties of the experience in terms of properties of the perceptual object to the extent that we still have a good perceptual grasp of the object. Consider seeing the cars coming from the opposite direction while you are driving upwards into a mountain in the early hours, on a foggy morning. At first, you see the cars through the fog. Then, as the fog gets thicker and thicker, there is a point beyond which it is more correct to say that you simply do not see the cars anymore, although you see moving objects through a thick layer of fog. Consider now the point just before this happens. It is less tempting here to assign the phenomenal properties of your foggy experience of the cars to the cars themselves. Things are even more straightforwardly so in the case of pretericeiving an object, which always and by its very nature happens "through a glass, darkly", 37 as it were, through the thick fog of time.

The second reason is that, pace Martin (2001), it isn't always the case ${ }^{38}$ that memory, or rather meminization, wears particularity on its sleeve. Suppose my weekly Saturday noon walking routine, which I have been doing for years, is this: after brunch at the Trout Inn, where I admire the beautiful peacocks, I cross River Thames, walk through Port Meadow, enjoying the green expanse and the calmly grazing cows, walk through Jericho quarter to reach University Parks, and walk through the park, along River Cherwell, all the way down to the deer park at Magdalen College, to finally lean against the wooden fence and watch the deer families enjoying their time in their sanctuary. I remember this routine. It took place in my personal past. But on which occasion? The occasions have been many and the phenomenology of my preteriception of this walking routine does not seem to be about any particular occasion (yet, I do claim that it is about one such particular occasion whenever I meminize the way just described, except I can't tell which; this makes the theory externalist, unlike constructivist views, which are internalist). Not so when I am performing this routine. As I walk by the cows at Port Meadow, I see the particular cows on a particular occasion. Always. This is why, again, in memory, there is less temptation and less reason than in perception to account for phenomenal properties in terms of properties of the objects that constitute the mental state. ${ }^{39}$

\footnotetext{
$\overline{37}$ To use a famous and beautiful biblical phrase from Corinthians $13: 12$.

38 And it is isn't what makes it essentially distinct from imagination-here simulationist constructivists have a point.

39 Though this feature -viz. the apparent lack of particularity-seems downright antithetical to what I have been arguing for in guise of a genuine direct realist view, there is no special problem here for such a realist: though the phenomenology of remembering does not wear particularity on its sleeve, as a matter of fact, each time I remember my walking routine, I remember particular places, objects, events, except I do not know which ones in terms of the particular occasions that I have been experientially confronted with them. This is what makes the theory externalist, and I don't see it as a disadvantage.
} 


\section{Conclusion}

To conclude, I have been trying to (1) argue that the extant, self-proclaimed direct realist views of episodic memory are timid when it comes to going all the way down the path of what direct realism requires, the model being the more prominent direct realism about perception, and (2) put forward, explicate, and defend a genuine direct realist view about episodic memory in guise of preteriception-memory as past-perception. I could not cover in this essay the rich empirical data on how exactly human memory works. It was not my goal and it would not have changed anything about the conceptual issues that I have discussed. However, for now, I would only note that some core empirical findings about human memory, such as that it is (re)constructive-generative rather than preservative, are, at a minimum, compatible with the philosophical idea of preteriception. I also believe they are, in fact, better explained by it than by other philosophical views, but I must leave this project for another time.

Acknowledgements I would like to thank audiences at Bilkent University and at the Centre for Philosophy of Memory at Université Grenoble Alpes. I presented parts of this paper at the Centre for Philosophy of Memory, Université Grenoble Alpes, as well as at Bilkent University and Bosphorus University. I am grateful to the audiences, especially To Kirk Michaelian, André Sant'Anna, Denis Perrin, Bill Wringe, Nazım Keven, Sandy Berkovski, Nick DiBella, Lucas Thorpe and Tufan Kiymaz. I am also grateful to three anonymous referees who offered extensive constructive comments that improved the paper.

\section{References}

Aranyosi, I. (2013). God, mind, and logical space: A revisionary approach to divinity. London: Palgrave Macmillan.

Aranyosi, I. (2020). Mental time travel and disjunctivism. Review of Philosophy and Psychology, 11(2), 367-384.

Bennett, J. (ed.). (2017). Early modern texts. Thomas reid, essays on the intellectual powers of man. https:// www.earlymoderntexts.com/assets/pdfs/reid1785essay3.pdf.

Bernecker, S. (2008). The metaphysics of memory. Berlin: Springer.

Child, W. (1992). Vision and experience: The causal theory and the disjunctive conception. Philosophical Quarterly, 42(168), 297-316.

Crane, T. (1998). Intentionality as the mark of the mental. In A. O'Hear (Ed.), Contemporary issues in the philosophy of mind. Cambridge: Cambridge University Press.

Crane, T. (2006). Is there a perceptual relation? In T. Gendler Szabó \& J. Hawthorne (Eds.), Perceptual experience (pp. 126-146). Oxford: Oxford University Press.

De Brigard, F. (2014). The nature of memory traces. Philosophy Compass, 9(6), 402-414.

Debus, D. (2008). Experiencing the past: A relational account of recollective memory. Dialectica, 62(4), $405-432$.

Dranseika, V. (2020). False memories and quasi-memories are memories. In T. Lombrozo, S. Nichols \& J. Knobe (Eds.), Oxford studies in experimental philosophy (Vol. 3, pp. 175-188).

Dretske, F. (1981). Knowledge and the flow of information. Cambridge, MA: MIT Press.

Evans, G. (1982). The varieties of reference. Oxford: Clarendon Press.

Fine, K. (1994). Essence and modality. Philosophical Perspectives, 8, 1-16.

Fodor, J. A. (1987). Psychosemantics. Cambridge, MA: The MIT Press.

French, C. (2018). Naive realism and diaphaneity. Proceedings of the Aristotelian Society, 118(2), 149-175.

Genone, J. (2016). Recent work on naive realism. American Philosophical Quarterly, 1, 1-25.

Gibson, J. J. (1966). The problem of temporal order in stimulation and perception. Journal of Psychology, 62, $141-149$.

Gibson, J. J. (1979). The ecological approach to visual perception. Boston: Houghton Mifflin.

Hutto, D. D., \& Myin, E. (2013). Radicalizing enactivism: Basic minds without content. Cambridge, MA: MIT Press. 
Ingram, D., \& Tallant, J. (2018). Presentism. In E. N. Zalta (Ed.), The stanford encyclopedia of philosophy, Spring 2018 Edition. https://plato.stanford.edu/archives/spr2018/entries/presentism/.

Jackson, F. (1977). Perception: A representative theory. Cambridge: Cambridge University Press.

Kim, J. (1973). Causation, nomic subsumption, and the concept of event. Journal of Philosophy, 70, 217-236.

Lewis, D. K. (1976). The paradoxes of time travel. American Philosophical Quarterly, 13(2), 145-152.

Loftus, E. F. (1993). The reality of repressed memories. American Psychologist, 48(5), 518-537.

Lowe, J. (1992). Experience and its objects. In T. Crane (Ed.), The contents of experience (pp. 79-104). Cambridge: Cambridge University Press.

Martin, M. G. F. (1997). The reality of appearances. In H. Logue \& A. Byrne (Eds.), Disjunctivism: Contemporary readings (pp. 91-116). Cambridge: MIT Press.

Martin, Michael G. F. (2001). Out of the past: Episodic recall as retained acquaintance. In C. Hoerl \& T. McCormack (Eds.), Time and memory (pp. 257-284). Oxford: Oxford University Press.

Martin, Michael G. F. (2004). The limits of self-awareness. Philosophical Studies, 120, 37-89.

Martin, Michael G. F. (2017). Elusive objects. Topoi, 36(2), 247-271.

Martin, C. B., \& Deutscher, M. (1966). Remembering. Philosophical Review, 75, 161-196.

McDowell, J. (1982). Criteria, defeasibility and knowledge. Proceedings of the British Academy, 68, $455-479$.

McDowell, J. (1984). De re senses. In C. Wright (Ed.), Frege: Tradition and influence. Oxford: Basil Blackwell.

McDowell, J. (1986). Singular thought and the extent of inner space. In P. Pettit \& J. McDowell (Eds.), Subject, thought and context. Oxford: Clarendon Press.

Michaelian, K. (2016). Mental time travel. Episodic memory and our knowledge of the personal past. Cambridge, MA: MIT Press.

O'Shaughnessy, B. (1980). The will (Vol. 2). Cambridge: Cambridge University Press.

Parfit, D. (1984). Reasons and persons. Oxford: Clarendon Press.

Perrin, D., \& Michaelian, K. (2017). Memory as mental time travel. In S. Bernecker \& K. Michaelian (Eds.), The Routledge handbook of philosophy of memory (pp. 228-239). New York: Routledge.

Robins, S. (2016). Representing the past: Memory traces and the causal theory of memory. Philosophical Studies, 173(11), 2993-3013.

Robinson, H. (1994). Perception. London: Routledge.

Ryle, G. (1954). Dilemmas: The tarner lectures 1953. Cambridge: Cambridge University Press.

Sant'Anna, A. (2020). The hybrid contents of memory. Synthese, 197, 1263-1290.

Schacter, D. L., \& Addis, D. R. (2007). The cognitive neuroscience of constructive memory: Remembering the past and imagining the future. Philosophical Transactions of the Royal Society London B Biological Scences, 362, 773-786.

Shoemaker, S. (1970). Persons and their pasts. American Philosophical Quarterly, 7(4), 269-285.

Snowdon, P. (1981). Perception, vision, and causation. In J. Dancy (Ed.), Perceptual knowledge. Oxford: Oxford University Press.

Snowdon, P. (1992). How to interpret direct perception. In T. Crane (Ed.), The contents of experience (pp. 48-78). Cambridge: Cambridge University Press.

Szpunar, K. K. (2010). Episodic future thought: An emerging concept. Perspectives on Psychological Science, 5(2), 142-162.

Travis, C. (2017). Deliverances (indirection). Topoi, 36(2), 229-246.

Tulving, E. (1972). Episodic and semantic memory. In Tulving \& W. Donaldson (Eds.), Organization of memory (pp. 381-402). New York: Academic Press.

Tulving, E. (2011). Origin of autonoesis in episodic memory. In H. L. Roediger, et al. (Eds.), The nature of remembering: Essays in Honor of Robert G. Crowder (pp. 17-34). Washington, DC: American Psychological Association.

Wilcox, S., \& Katz, S. (1981). A direct realistic alternative to the traditional conception of memory. Behaviorism, 9(2), 227-239.

Publisher's Note Springer Nature remains neutral with regard to jurisdictional claims in published maps and institutional affiliations. 